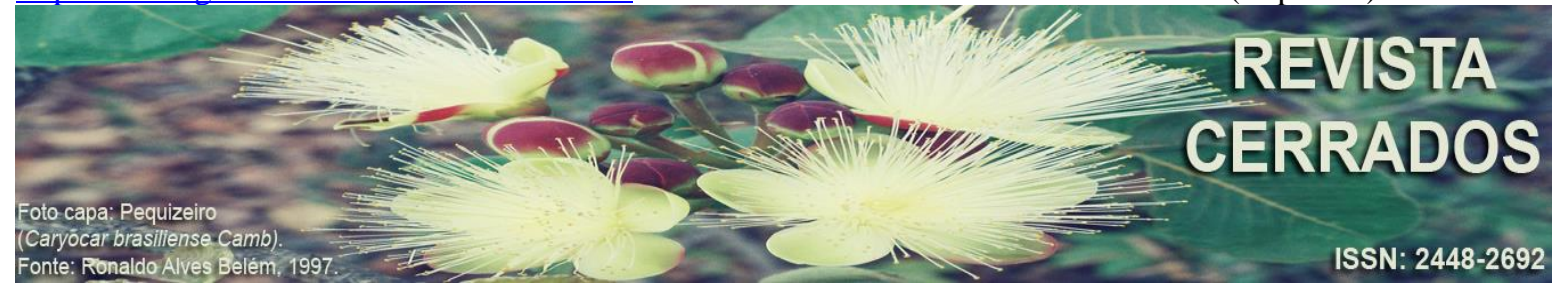

\title{
NATUREZA EM MOVIMENTO: investigações desenvolvidas por Dirce Suertegaray para estudos sobre arenização ${ }^{1}$
}

\section{NATURE IN MOVEMENT: investigations developed by Dirce Suertegaray for sandization studies}

\section{NATURALEZA EN MOVIMIENTO: investigaciones desarrolladas por Dirce Suertegaray para estudios sobre arenización}

\author{
Ivamauro Ailton de Sousa Silva \\ Universidade Federal do Rio Grande do Sul - UFRGS, Porto Alegre, \\ Rio Grande do Sul, Brasil \\ E-mail: <ivamauro@hotmail.com>.
}

\begin{abstract}
RESUMO
Esse texto apresenta as contribuições teóricas e metodológicas, desenvolvidas por Dirce Suertegaray, para os estudos sobre o processo de arenização. A finalidade é demostrar as trajetórias, a produção e a divulgação do conhecimento científico, conduzidas no âmbito da ciência geográfica brasileira e, em particular, nos estudos da natureza. $\mathrm{O}$ artigo foi construído, por meio de análise documental, de revisão bibliográfica e de análise comparativa entre as localidades pesquisadas: Quaraí (RS), Paranavaí (PR), Reserva do Cabaçal (MT), cerrado paulista, sudoeste de Goiás, Buritizeiro (MG), Gilbués (PI) e Manaus (AM). Com base nessas informações, procedeu-se à organização e à indicação dos aportes e dos itinerários metodológicos, instrumentos que desempenharam as discussões essenciais da pesquisa. Nas abordagens conduzidas pela autora, o enfoque, a partir dos estudos da natureza, foi utilizado como prioridade, para explicar a gênese e para interpretar as dinâmicas dos areais de Quaraí, no sudoeste do estado do Rio Grande do Sul. Os resultados da pesquisa demonstram que a natureza em movimento é responsável pela origem dos areais, mas as atividades sociais, realizadas de forma inadequada, promovem a intensificação do processo de arenização, em distintas localidades do território brasileiro. Nesse sentido, o papel desempenhado por Dirce Suertegaray revela a importância de uma geografia articulada, carregada de pluralidade e de conexões.
\end{abstract}

Palavras-chave: Natureza. Contribuições. Geógrafa Dirce Suertegaray. Arenização.

\footnotetext{
${ }^{1}$ Discussão ajustada e ampliada do artigo publicado no "XIII ENANPEGE - A Geografia Brasileira na Ciênciamundo: produção, circulação e apropriação do conhecimento", realizado de 2 a 7 de setembro de 2019, em São Paulo - SP.
} 
SILVA, I. A. S.

Natureza em movimento: investigações desenvolvidas por Dirce Suertegaray para estudos sobre arenização

\begin{abstract}
This text presents the theoretical and methodological contributions developed by Dirce Suertegaray for studies regarding the sandization process. The purpose is to demonstrate the trajectories, production and dissemination of scientific knowledge conducted within the scope of Brazilian geographic science and, in particular, in studies in the field of nature. The article was developed by means of a documentary analysis, bibliographic review and comparative analysis between the researched localities of Quaraí (RS), Paranavaí (PR), Reserva do Cabaçal (MT), cerrado paulista, southwest of Goiás, Buritizeiro (MG), Gilbués (PI) and Manaus (AM). Based on this information, the contribution and methodological itinerary organization and indications were carried out, instruments that accomplished the essential research discussions. In the approaches conducted by the aforementioned author, the focus based on nature studies was used as a priority to explain Quaraí sand genesis and interpret its dynamics in southwestern Rio Grande do Sul. The research results demonstrate that nature in motion it is responsible for the origin of the sands, but that social activities carried out inappropriately result in sandization process intensification in different locations in the Brazilian territory. The role played by Dirce Suertegaray reveals the importance of an articulated geography, charged with plurality and connections.
\end{abstract}

Keywords: Nature. Contributions. Geographer Dirce Suertegaray. Sandization.

\title{
RESUMEN
}

Este texto presenta las contribuciones teóricas y metodológicas, desarrolladas por Dirce Suertegaray, para estudios sobre el proceso de arenización. El propósito es demostrar las trayectorias, la producción y la difusión del conocimiento científico, realizado dentro del alcance de la ciencia geográfica brasileña y, en particular, de los estudios de la naturaleza. El artículo fue construido, mediante análisis documental, revisión bibliográfica y análisis comparativo entre los lugares investigados: Quaraí (RS), Paranavaí (PR), Reserva do Cabaçal (MT), cerrado paulista, suroeste de Goiás, Buritizeiro (MG), Gilbués (PI) y Manaus (AM). Con base en esta información, se llevaron a cabo la organización y la indicación de contribuciones e itinerarios metodológicos, instrumentos que realizaron las discusiones esenciales de la investigación. En las investigaciones realizadas por esta autora, el enfoque de los estudios de la naturaleza utilizó como prioridad, explicar la génesis e interpretar la dinámica de los arenales de Quaraí, ciudad del suroeste del estado de Rio Grande do Sul. Los resultados de la investigación demuestran que la naturaleza en movimiento es responsable del origen de las arenas, pero las actividades sociales, llevadas a cabo de manera inapropiada, promueven la intensificación del proceso de arenización, en diferentes lugares del territorio brasileño. En este sentido, el papel desempeñado por Dirce Suertegaray revela la importancia de una geografía articulada, cargada de pluralidad y conexiones.

Palabras-clave: Naturaleza. Contribuciones. Geógrafa Dirce Suertegaray. Arenización. 
SILVA, I. A. S.

Natureza em movimento: investigações desenvolvidas por Dirce Suertegaray para estudos sobre arenização

\section{INTRODUÇÃO}

Dirce Maria Antunes Suertegaray tem sido, nas últimas décadas, um nome de destaque na comunidade de geógrafas e geógrafos brasileiros. Conseguiu manter, com autenticidade, o equilíbrio entre as geografias (Física e Humana) na construção de uma geografia articulada, carregada de pluralidade e conexões. O reconhecimento desses esforços fez com que suas obras proporcionassem leituras e produção do conhecimento geográfico em todo o território brasileiro.

A redação de artigos, publicação de diversos livros $^{2}$ como autora/coautora e capítulos de livros revelam as qualidades e ferramentas poderosas de estudo, de análise e reflexão, com a construção de inúmeros artigos e orientações de pesquisas responsáveis pelo avanço da geografia brasileira. Por meio de suas contribuições teóricas e metodológicas no âmbito da geografia, Dirce Suertegaray tem sua trajetória marcada pelo reconhecimento que se evidenciou a partir da integração de importantes estudos sobre natureza, especialmente sobre o processo de arenização.

A arquitetura deste texto foi uma escolha adequada para o perfil da referida autora, destacando sua atuação na geografia brasileira e a importância dos seus trabalhos na construção de pesquisas que influenciam estudantes de geografia, professores, alunos, exorientandos e atuais. A intencionalidade aqui não é a de realizar uma retrospectiva de sua produção e trajetória na geografia, mas apresentar as influências teóricas desenvolvidas por Dirce Suertegaray no âmbito dos estudos da natureza. De forma complementar, o texto pretende também enfatizar as contribuições teóricas, as metodologias utilizadas por Dirce Suertegaray na construção das bases conceituais para a interpretação da origem e dinâmica do processo de arenização, no sudoeste do Rio Grande do Sul, conceito fundante da sua tese.

Para a realização da pesquisa, primeiramente foi realizado um estudo teórico sobre temas referentes ao processo de arenização. Em seguida, elaboraram-se os mapas temáticos indicando as áreas com estudos sobre arenização e processos similares. Por fim, foi possível realizar a organização e indicação das contribuições e dos itinerários metodológicos - instrumentos que desempenharam os resultados e as discussões da pesquisa.

\footnotetext{
${ }^{2}$ Deserto Grande do Sul: controvérsias, Geografia física e geomorfologia: uma releitura, Terra: feições ilustradas, Arenização Natureza Socializada, Brasil: feições ilustradas, (Re) ligar a Geografia, Brasil: feições arenosas, entre tantos outros).
} 
SILVA, I. A. S.

Natureza em movimento: investigações desenvolvidas por Dirce Suertegaray para estudos sobre arenização

\section{Metodologia}

Os procedimentos utilizados durante o desenvolvimento da pesquisa correspondem aos fundamentos operacionais adotados em três diferentes etapas. Iniciou- por pela revisão bibliográfica para aquisição de bases teórico-metodológicas disponíveis em artigos, capítulos de livros, livros, dissertações e teses. A busca dos materiais bibliográficos foi realizada em periódicos especializados em Geografia e em bancos de dados online (repositórios institucionais de universidades) e no catálogo de teses disponibilizado pela Coordenação de Aperfeiçoamento de Pessoal de Nível Superior (Capes).

Em seguida realizou-se a análise do mapeamento das áreas com pesquisas sobre arenização indicando a estrutura espacial do processo no território brasileiro. Os mapas foram elaborados por Silva; Suertegaray (2018) a partir de informações georreferenciadas e da utilização de ferramentas dos Sistemas de Informações Geográficas (SIG), tais como o ArcGIS. Esse mapeamento foi desenvolvido utilizando-se estudos realizados nos estados do Rio Grande do Sul, Amazonas, Goiás, Paraná, São Paulo, Minas Gerais, Piauí e Mato Grosso.

$\mathrm{Na}$ última etapa, realizou-se a análise comparativa das áreas pesquisadas situadas no Rio Grande do Sul, Amazonas, Goiás, Paraná, São Paulo, Minas Gerais, Piauí e Mato Grosso. Este comparativo permitiu destacar os indicadores do processo arenização e enfatizar diferenças e semelhanças associadas às características físico-naturais em distintas localidades do Brasil interiorizado.

\section{Geografia: Itinerários e conexões}

Estabelecer conexões é fundante na geografia e faz parte da conjectura geográfica adotada pela Dirce. Em sua tese de doutorado em geografia física, intitulada A trajetória da natureza: um estudo geomorfológico sobre os areais de Quaraí-RS, orientada pelo Prof. Adilson Avansi de Abreu e defendida na USP em abril de 1988. A pesquisa promoveu essa conexão (natureza e sociedade), princípio que foi aparentemente perdido pela geografia. Nas palavras de Dirce: a geografia é a ciência das relações, a ciência das conexões! 
SILVA, I. A. S.

Natureza em movimento: investigações desenvolvidas por Dirce Suertegaray para estudos sobre arenização

\section{A trajetória da natureza: os areais de Quaraí-RS}

Quando criança, nos campos da tia Amélia,

Brinquei nos areais, ao sol do meio-dia.

Era proibido brincar, ao sol do meio-dia.

Quando adulto, nos campos da tia Amélia,

Voltei aos areais.

Ao sol do meio-dia, lá eles não estão mais.

(Areais, Suertegaray, 1987).

Figura 1 - Ilustração dos areais

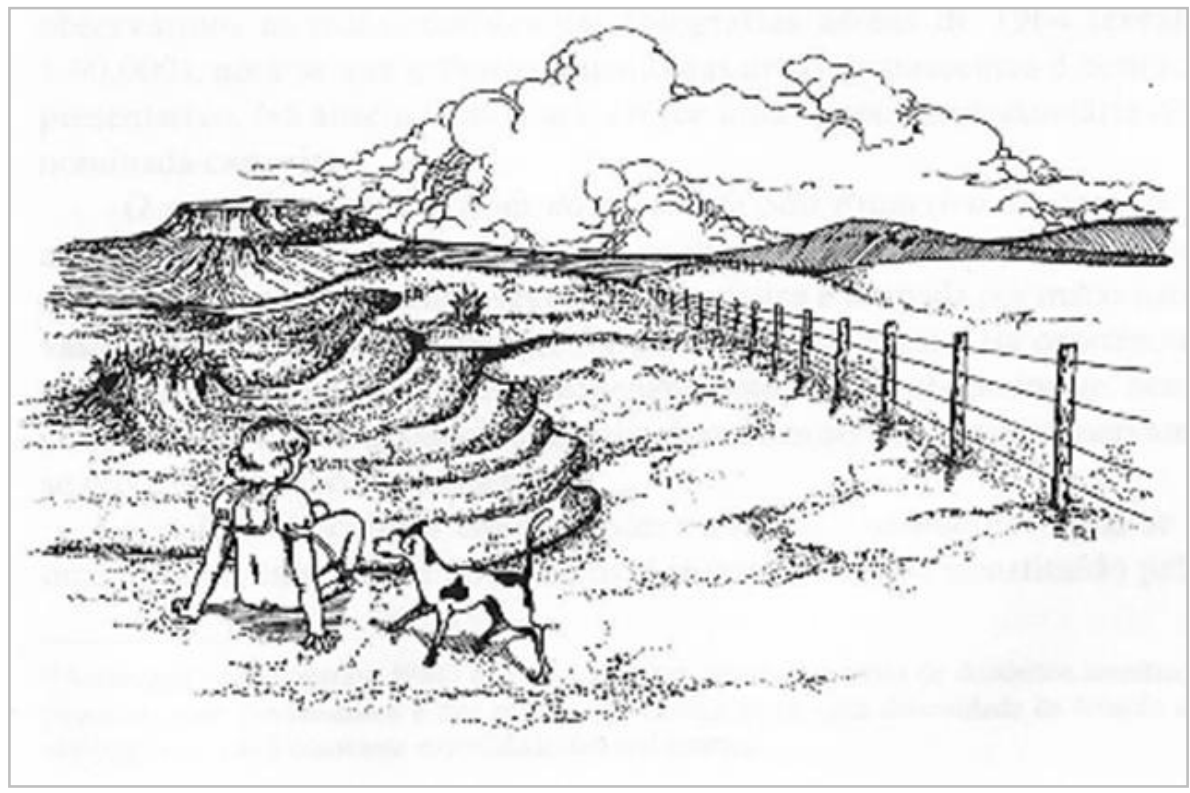

Fonte: Suertegaray (1998).

A construção da tese elaborada por Dirce Suertegaray iniciou-se em 1983, com o tema desertificação, embora a pesquisa assumisse trajetórias diferentes durante sua conclusão, com novas interpretações sobre os areais. $\mathrm{O}$ tema foi produto da difusão da desertificação no Rio Grande do Sul (RS), anos 1970/1980, pela imprensa que se divulgava que o estado estava com problemas de erosão do solo na região sudoeste (Campanha gaúcha) e que poderia se transformar em um deserto.

Deste modo, a fisionomia da paisagem constituída por manchas arenosas era chamada de desertos. Essas feições arenosas, ao longo do tempo, foram definidas por muitos pesquisadores como desertos (CORDEIRO; SOARES, 1977) e desertificação (SOUTO, 1985). A divulgação jornalística também apresentou discussões sobre esse assunto, caracterizando as áreas arenosas como processo de desertificação. 
SILVA, I. A. S.

Natureza em movimento: investigações desenvolvidas por Dirce Suertegaray para estudos sobre arenização

Nesse momento, segundo Dirce Suertegaray, a discussão ambiental era emergente no RS e o tema desertificação foi introduzido no estado a partir da difusão da existência dos areais. Essa problemática a induziu a estudar esse processo, já que o tema oferecia oportunidade para analisar novamente a relação/conexão natureza e sociedade. Essas áreas com ocorrência de areais (Figura 2) estão presentes no município em que ela nasceu, Quaraí.

Figura 2 - Os areais de Quaraí, sudoeste do Rio Grande do Sul

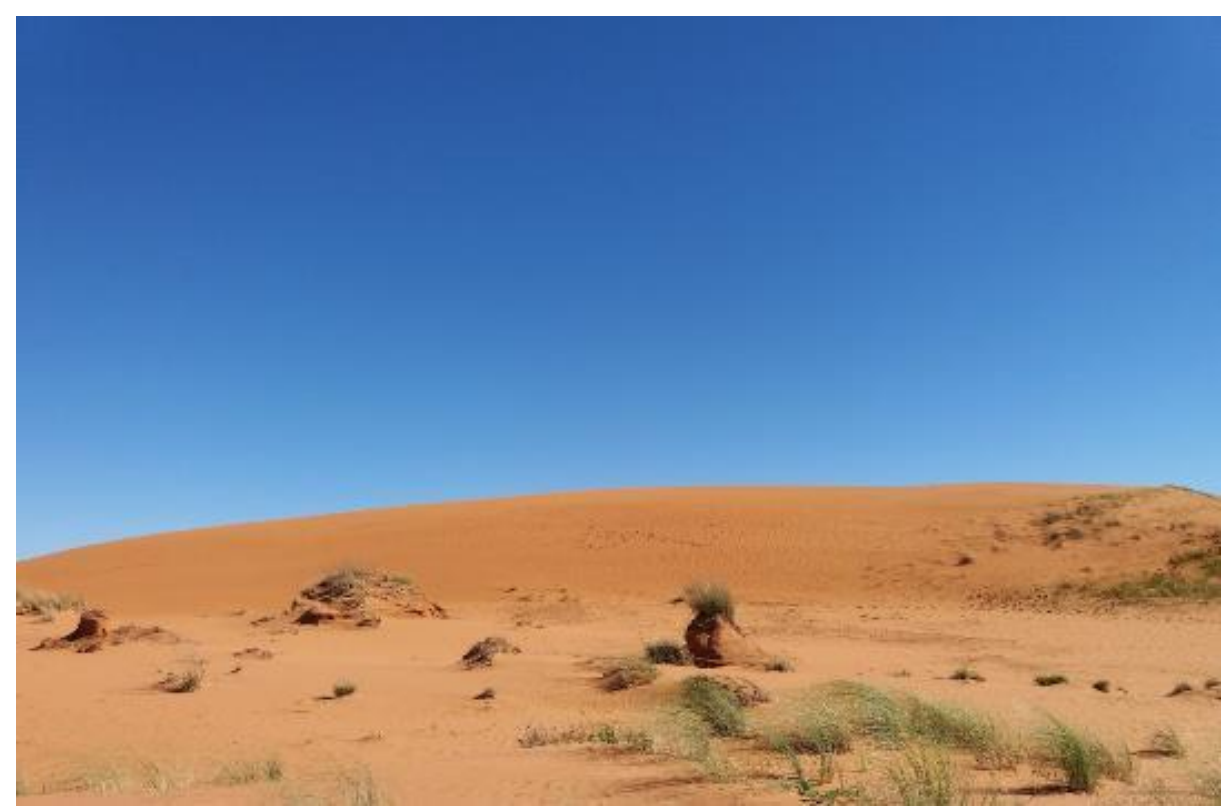

Fonte: Dirce Suertegaray (2020).

A pesquisa de Suertegaray (1987) buscou inserir uma confirmação divergente. A mídia jornalística na época indicava que os areais eram decorrentes da expansão da monocultura de soja. Essa hipótese não se confirmou em sua tese porque os elementos da dinâmica da natureza e os registros históricos da ocorrência dessas feições demonstravam origem natural, podendo ser intensificados pela atividade humana. De acordo com Dirce Suertegaray, os viajantes naturalistas alemães (Século XIX) já tinham descrito esses areais como pode ser observado na descrição feita por Avé-Lallemant (1858), quando em viagem por aquela região:

A lua um pouco velada deitava um clarão turvo sobre a região. Subitamente, em torno de nós tudo parecia branco. Crer-se-ia viajar num campo de neve. Em volta, a areia pura, limpa, sem nenhuma vegetação, verdadeiro deserto africano embora de pouca extensão. Dava-me uma impressão particularmente melancólica. Viajamos juntos em silêncio" (AVÉ-LALLEMANT, 1980, p. 322 referenciado por SUERTEGARAY, 2012, p. 139).

Revista Cerrados, Montes Claros/MG, v. 18, n. 1, p. 331-351, jan./jun.-2020. 
SILVA, I. A. S.

Natureza em movimento: investigações desenvolvidas por Dirce Suertegaray para estudos sobre arenização

Merece ser destacado, também como referência, o relato de Rambo (1956):

Em alguns lugares mais altos e planos depararam-se um fenômeno único em todo o Rio Grande do Sul: areais de muitos hectares de superfícies no meio campo, como verdadeiras dunas continentais: é como se a paisagem quisesse conservar uma lembrança do que foi toda essa região nas longínquas eras do Triássico, quando ainda não existia a valente flora de campo para subjugar os areais (RAMBO, 1956 referenciado por SUERTEGARAY, 1996, p. 39).

Para Suertegaray (1987), este relato tem um importante significado na medida em que expressa a ocorrência de areais de grande extensão, pressupondo um fato decorrente da dinâmica da natureza. Historicamente, a toponímia areal usada por Rambo (1956) demonstra o reconhecimento dessas feições em um período que é anterior à expansão da cultura da soja na região do sudoeste do RS.

Nesse sentido, os registros históricos encontrados e difundidos na tese de Suertegaray (1987) indicam que a ocorrência dos areais antecede os processos de apropriação da natureza por razões socioeconômicas. Deste modo, não havia como associar soja aos areais que já estavam presentes na paisagem.

Ao aprofundar a leitura e análise dos trabalhos sobre esse tema, verificou-se que a pesquisa desenvolvida por Suertegaray (1987) foi a única que abordou os areais na perspectiva geográfica/geomorfológica, estabelecendo conexões. Por isso seu trabalho foi considerado inovador no âmbito da originalidade e metodologia.

O renomado geógrafo brasileiro Aziz Ab'Saber, em seu artigo A revanche dos ventos: derruição de solos areníticos e formação de areais na Campanha Gaúcha, faz diversas referências sobre a pesquisa de Dirce Suertegaray (1987), demostrando admiração pelo seu trabalho na área de geomorfologia. Esse autor considera sua tese inovadora, pois produziu resultados ricos em observações e registros, revelando análises sob a ótica convergente dos trabalhos (CORDEIRO; SOARES, 1977; SOUTO, 1985) desenvolvidos no sudoeste do RS. No artigo elaborado por Ab'Sáber, verifica-se esse reconhecimento:

Dirce Suertegaray vem pesquisando com insistência e determinação as manchas de areais de todos sub-espaços do sudoeste gaúcho. São mais de dez anos de pesquisas ininterruptas [...]. Dirce entrou mais fundo que seus antecessores na recuperação das vicissitudes da história agrária regional para explicar o nível de antiguidade de alguns areais gaúchos e identificar rupturas aceleradoras dos processos erosivos eólicos. Nesse sentido, a autora fez incursões no campo da história oral [...] (AB'SÁBER, 1995, p. 10). 
SILVA, I. A. S.

Natureza em movimento: investigações desenvolvidas por Dirce Suertegaray para estudos sobre arenização

Ab’Sáber defende como possibilidade metodológica as referências históricas, pois elas permitem reconhecer o grau de antiguidade relativa dos processos responsáveis pela gênese de ocorrências de areões da Campanha Gaúcha. Assim, destaca que Dirce Suertegaray "entrou fundo na discussão do antigo topônimo Areal e Rincão do Areal, onde a ocorrência de arẽ̃es tem um grau de antiguidade maior, não tendo vínculos com a expansão da agricultura mecanizada e ou usos inadequados recentes dos solos regionais" [...] (AB'SÁBER, 1995, p. 11).

O autor destaca que essa análise histórica do povoamento e da utilização do espaço realizada por Dirce Suertegaray merece grandes elogios e indica detalhes seguros, corretos e inusitados sobre assuntos aparentemente impossíveis de serem interpretados. Diante das explicações sobre a gênese dos areais de Quaraí, Suertegaray (1987) conseguiu comprovar que essas feições são decorrentes da dinâmica da natureza, estando, portanto, associadas à intensificação do escoamento superficial concentrado em clima úmido, em região com pouca vegetação. Posteriormente, vários estudos de orientandos (BELLANCA, 2002; PIRES DA SILVA, 2008), juntamente com estudos desenvolvidos por Verdum (1997), corroboram essa tese.

Entretanto, além da gênese (natural ou antrópica), outra problemática teria de ser resolvida. Ao aprofundar as leituras e discussões sobre o processo desertificação e incluir em suas análises as condições climáticas (ausência de aridez, abundância hídrica e pluviosidade em torno de $1.400 \mathrm{~mm} / \mathrm{ano}$ ), Suertegaray (1987) considerou inadequado o uso do termo/conceito desertificação para explicar a dinâmica dos areais que ocorriam na paisagem de Quaraí. Assim, Dirce Suertegaray mais uma vez "provoca" a comunidade científica ao questionar o uso do conceito de desertificação para os areais de Quaraí. Nesse contexto de investigação, verificou a necessidade de explicar que processo seria aquele, emergindo então a pergunta: se não é desertificação, o que é?

A tarefa, segundo Dirce Suertegaray, foi buscar uma tentativa de explicação para os processos ali ocorridos. A dinâmica e os fatores condicionantes já eram compreendidos, mas como poderiam ser denominados? As referidas feições são reconhecidas pela toponímia regional como areais e arenal, logo, Dirce usou a representação desses lugares e derivou do termo areal o conceito "arenização", que surge pela primeira vez em sua tese.

Ela conta, de maneira simples, que fez isso de forma muito intuitiva e não tinha ideia de que a construção desse conceito fosse ser o fundante da tese. Tratava-se da Revista Cerrados, Montes Claros/MG, v. 18, n. 1, p. 331-351, jan./jun.-2020. 
SILVA, I. A. S.

Natureza em movimento: investigações desenvolvidas por Dirce Suertegaray para estudos sobre arenização

elaboração de um conceito que explicava um fenômeno da natureza que ainda não havia sido caracterizado cientificamente.

Em sua tese, o fenômeno arenização é conceituado como "o processo de retrabalhamento de depósitos arenosos pouco ou não consolidados, que promove, nessas áreas, uma dificuldade de fixação da cobertura vegetal, devido à intensa mobilidade de sedimentos arenosos pela ação das águas e dos ventos" (SUERTEGARAY, 1998, p. 71). O processo está restrito a regiões de clima úmido e, embora períodos de estiagem sejam comuns, é um fenômeno que envolve erosão, transporte e acumulação.

Já o processo de desertificação é reservado para expressar a degradação do solo, vegetação e água em condições climáticas adequadas, bem como períodos secos prolongados, baixos índices pluviométricos e presença de aridez (SUERTEGARAY, 2006). Ao contrário, a dinâmica dos processos envolvidos na arenização deriva essencialmente da abundância de água, sendo um elemento importante para diferenciar os dois processos.

Suertegaray (1987) afirma que a elevada precipitação, em particular aquela concentrada em chuvas torrenciais, favorece os processos de escoamento, potencializando a formação de ravinas e voçorocas - feições resultantes do escoamento hídrico. Desta feita, o clima se constitui como o grande responsável pela dinâmica processual do processo de arenização devido à ocorrência de excedentes hídricos que vão se acumular na superfície do solo e escoar pelo terreno, potencializando a erosão na paisagem em áreas com fragilidade.

Essa trajetória e deciframento promovidos por Dirce Suertegaray, sem dúvida, contribuíram para os estudos no âmbito da natureza, reforçando a importância de estabelecer conexões e apontar críticas na tentativa de evitar equívocos sobre as dinâmicas naturais da paisagem. A tese despontou escalas locais e ganhou repercussões maiores (regional), conduzindo para o debate nacional, uma vez que os areais do sudoeste do RS eram conhecidos e divulgados pela impressa e pesquisadores como desertos e desertificação.

Em 1992, essa repercussão foi publicada no Jornal do Brasil. O conteúdo jornalístico foi dedicado à área de Ecologia, destacando o avanço da desertificação no nordeste brasileiro (Figura 3). Os editores da reportagem organizam a matéria e incluem separadamente a discussão sobre os areais do RS, com a participação especial de Dirce Suertegaray. Na época, com 41 anos, a jovem pesquisadora esclareceu: 
SILVA, I. A. S.

Natureza em movimento: investigações desenvolvidas por Dirce Suertegaray para estudos sobre arenização

Foi a própria natureza e não a ação do homem que formou os $15,6 \mathrm{~km}^{2}$ de areais na região sudoeste do estado. A expressão areais, usada pela pesquisadora Dirce Suertegaray, do Instituto de Geografia da Universidade Federal do Rio Grande do Sul (UFRGS), é justamente para evitar, segundo ela, o uso do termo desertificação. "A Conferência de Nairóbi (no Quênia), em 1977, usou como conceito de desertificação o que ocorre por uma ação humana", define.

Nas imensas várzeas e coxilhas dos campos de Quaraí, Alegrete, São Francisco de Assis, Cacequi e Santiago, a água escorreu por morros e encostas e o fluxo dessa enxurrada, a cada ponto de encontro, foi criando ravinas (sulcos na terra pela água da chuva) e vassoramentos ou grandes fendas que atingem o lençol freático, levando de roldão as raízes das plantas e matéria orgânica. Para ela, assim nasceu a paisagem estéril, que apesar da aparência, não pode ser classificada como deserto [...].

Dirce explica que as areias brancas e a ausência de vegetação de Alegrete decorrem do próprio processo natural [...]. Ela acrescenta também que a região é úmida chove de 1.400 a 1.500 milímetros anuais, com uma média superior a 100 milímetros por mês. O clima é subtropical e aí está a diferença básica do Nordeste, onde o clima é semi-árido e a terra fica estéril pela falta d'água [...].

Figura 3 - Matéria Jornalística sobre desertificação e arenização no Brasil, com a participação da Prof. Dirce

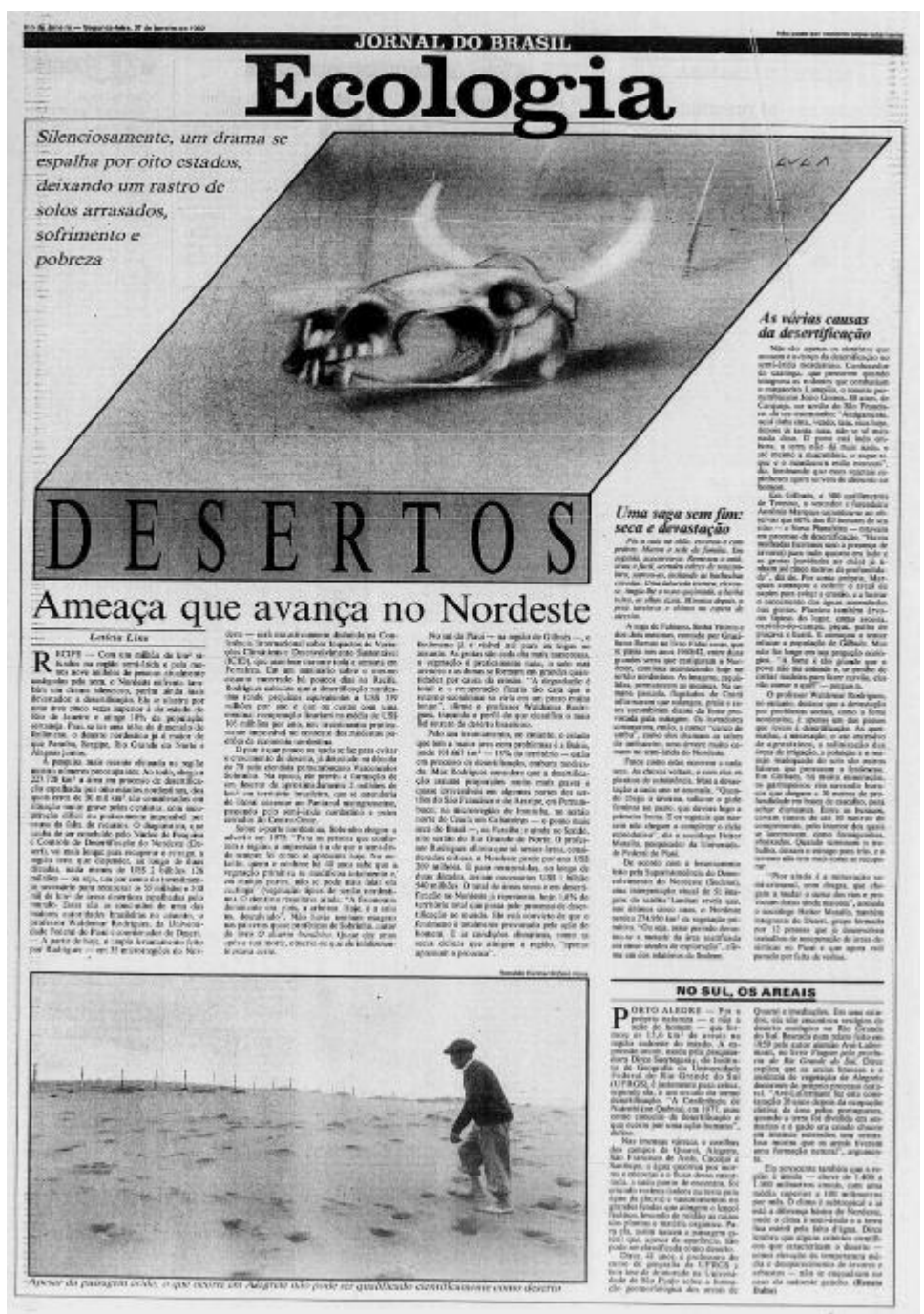

Fonte: Jornal Brasil (1992).

Revista Cerrados, Montes Claros/MG, v. 18, n. 1, p. 331-351, jan./jun.-2020. 
SILVA, I. A. S.

Natureza em movimento: investigações desenvolvidas por Dirce Suertegaray para estudos sobre arenização

As discussões promovidas e a "ousadia" da Profa. Dirce permitiu uma postura crítica e divergente em relação aos textos e autores que ela utilizou durante a construção da sua tese. Com base em seus estudos, o Ministério do Meio Ambiente (MMA) exclui os areais do sudoeste do RS do mapa das regiões com ocorrência/suscetibilidade a desertificação e os classifica como "áreas de atenção especial” (Figura 4).

Figura 4 - Mapa de ocorrência de desertificação e áreas de atenção especial

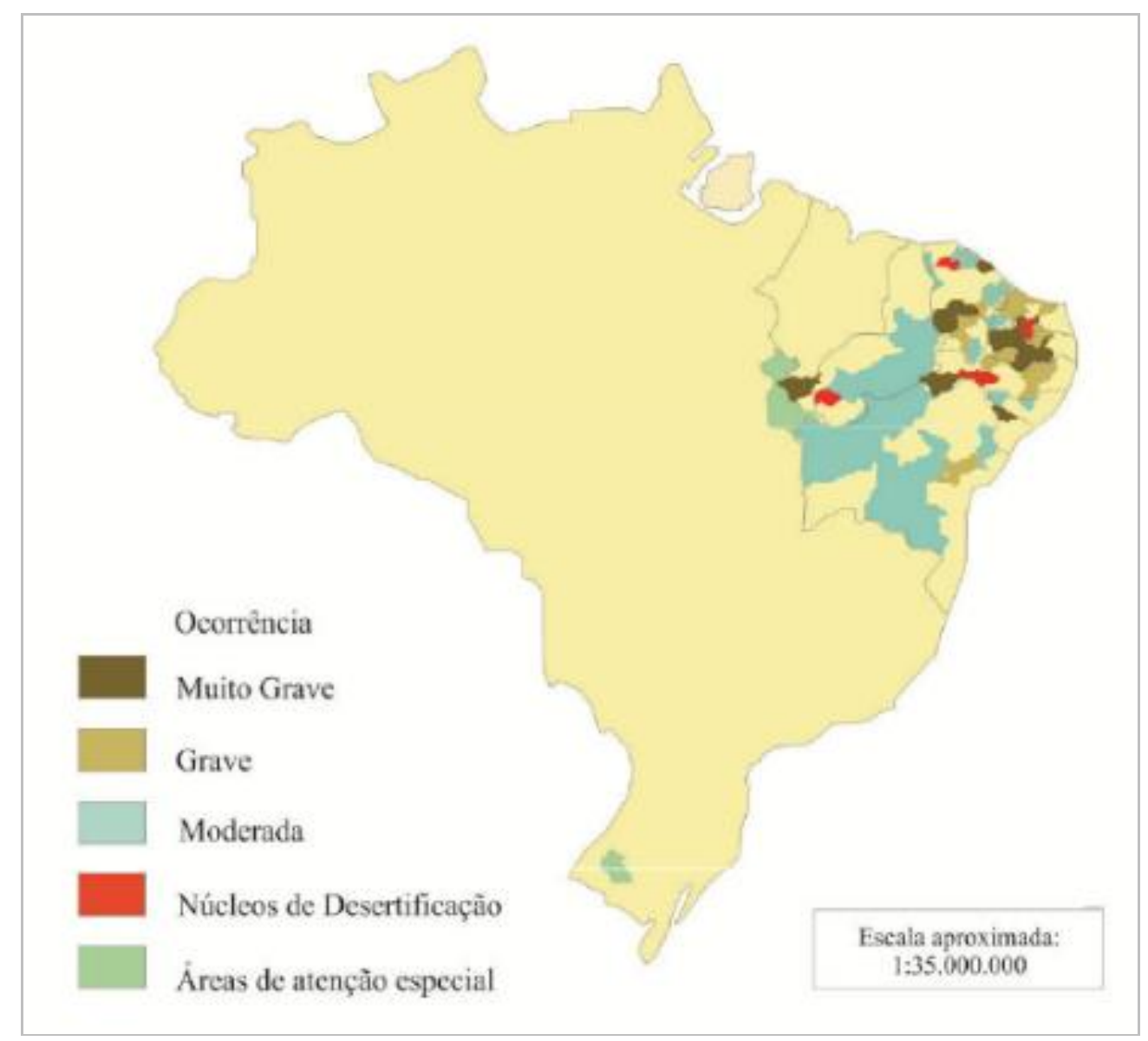

Fonte: Ministério do Meio Ambiente (1992) apud Suertegaray et. al. (2001).

O mapa elaborado pelo MMA (1992) identifica espacialmente as áreas com risco de desertificação, sendo visível a não inclusão do Rio Grande do Sul neste processo. A pesquisa de Dirce Suertegaray permitiu um posicionamento crítico e forneceu um panorama essencial da ciência geográfica: a conexão natureza e sociedade, admitindo um diálogo permanente e formador no campo da geografia, com posições ideologicamente divergentes. 
SILVA, I. A. S.

Natureza em movimento: investigações desenvolvidas por Dirce Suertegaray para estudos sobre arenização

\section{Arenização no Brasil: distribuição, características e fatores condicionantes}

Nos últimos anos, o conceito de arenização vem sendo utilizado entre pesquisadores de outros estados brasileiros para caracterizar o surgimento e expansão de áreas arenosas (SILVA; SUERTEGARAY, 2018). O conceito vem sendo empregado e reconhecido, especialmente no Brasil, em pesquisas desenvolvidas nos estados do Amazonas, Paraná, Goiás, São Paulo, Minas Gerais, Piauí e Mato Grosso (Figura 5).

Figura 5 - Mapa de localização das áreas com pesquisas sobre arenização

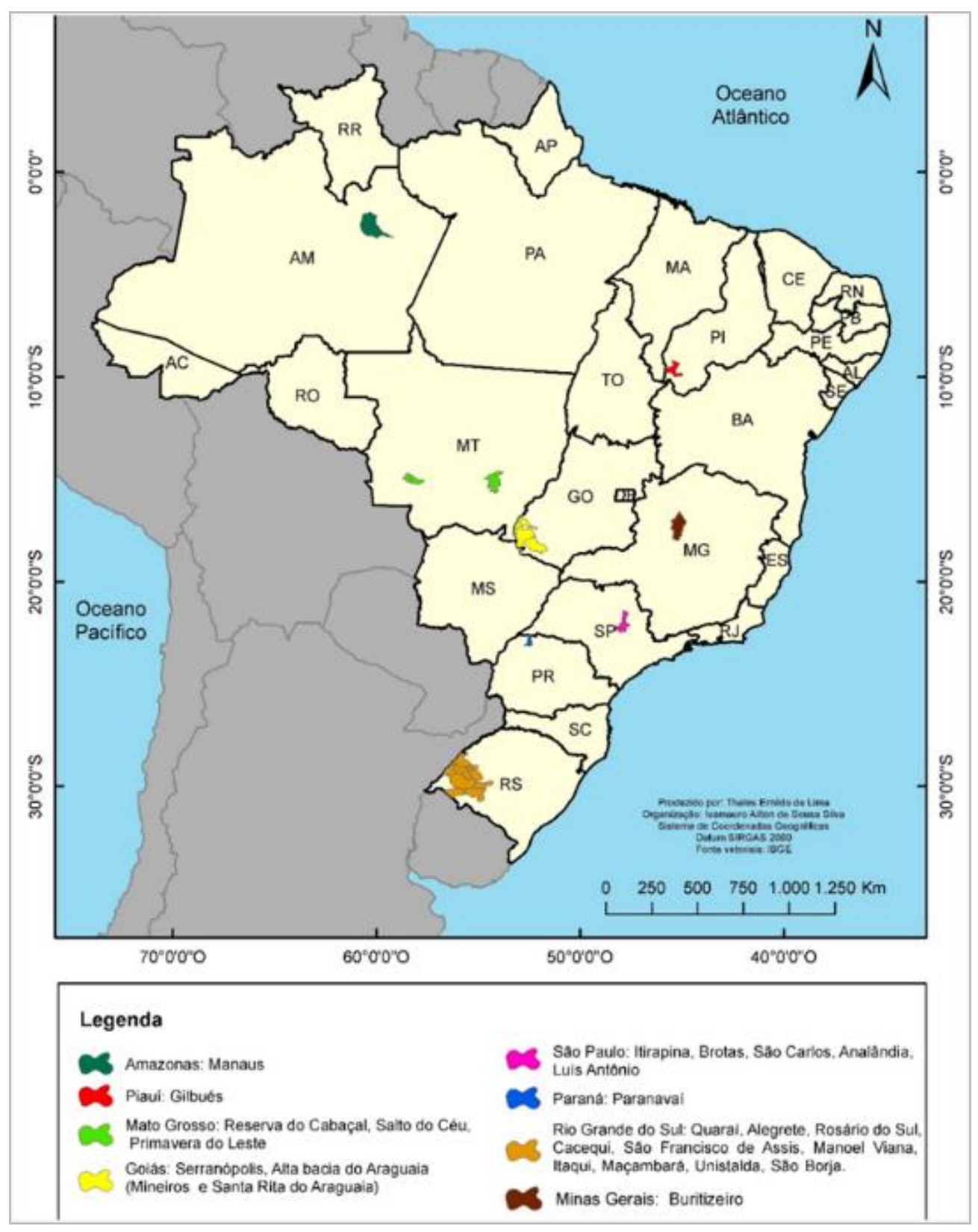

Fonte: SILVA; SUERTEGARAY (2018).

Revista Cerrados, Montes Claros/MG, v. 18, n. 1, p. 331-351, jan./jun.-2020. 
SILVA, I. A. S.

Natureza em movimento: investigações desenvolvidas por Dirce Suertegaray para estudos sobre arenização

A difusão do conceito recebeu proporção nacional através dos estudos já elaborados por Dirce Suertegaray, assim como daqueles que derivam da continuidade de suas pesquisas. Para fundamentar tais afirmações, foi necessária uma ampla revisão bibliográfica sobre as características da paisagem e as dinâmicas processuais das áreas nas quais o processo de arenização se manifesta.

A distribuição espacial do fenômeno da arenização, além do Rio Grande do Sul, ocorre em áreas situadas nos estados do Amazonas, Paraná, Goiás, São Paulo, Minas Gerais, Piauí e Mato Grosso. Os detalhes relativos à gênese, aos fatores e dinâmicas atuantes foram explicados por diferentes pesquisadores e estão apresentados a seguir.

No estado do Amazonas, Albuquerque (1999) adotou o conceito de arenização para caracterizar as manchas arenosas na bacia hidrográfica do Igarapé do Leão, em Manaus. Os resultados encontrados pela autora indicam que o processo é decorrente do material de origem, textura do solo e chuvas intensas, ocasionado, também, pelo desmatamento e queimadas, que são procedimentos comuns na localidade para a limpeza do terreno.

Em Goiás, Antunes (2006) aponta que o uso e manejo inadequado dos solos, associados à ocorrência dos Neossolos Quartzarênicos Órticos, têm relação com o surgimento da arenização. Essa mesma constatação foi verificada por Silva (2006), que conferiu a presença de areais relacionados aos solos arenosos submetidos a usos e manejos pecuários inadequados, associados também aos processos erosivos hídricos em setores de convergência de fluxos superficiais potencializados pela ação das águas das chuvas concentradas.

Em Paranavaí-PR, a pesquisa desenvolvida por Stipp (2006) revela que as condições climáticas atuam de maneira conjunta e produzem diferentes resultados no desencadeamento dos processos de voçorocamento e arenização, em função das características locais de declividade e exposição das forças erosivas. Além desses fatores, Stipp (2006) conclui que o processo de arenização é ocasionado pela energia hídrica e por fatores de transporte e acumulação dos solos arenosos em ambientes de clima subtropical úmido. Os resultados da pesquisa de Stipp (2006) evidenciam que a dinâmica da natureza também é responsável pela gênese de processos erosivos devidos à fragilidade ambiental, mas as intervenções antropogênicas, de forma desiquilibrada, provocam a permanência e aceleração desses fenômenos.

Em São Paulo, as pesquisas sobre arenização foram conduzidas inicialmente por Seabra (2006) e Quaresma (2008). Os autores analisaram a fragilidade das terras e Revista Cerrados, Montes Claros/MG, v. 18, n. 1, p. 331-351, jan./jun.-2020. 
SILVA, I. A. S.

Natureza em movimento: investigações desenvolvidas por Dirce Suertegaray para estudos sobre arenização

identificaram manchas arenosas em áreas suscetíveis no cerrado paulista, especificamente nos municípios de Analândia, Brotas Itirapina, São Carlos e Luís Antônio. Segundo Seabra (2006), o processo de arenização ocorre sob áreas de reduzida biomassa, evoluindo para manchas arenosas ou areais, passando por feições de degradação como áreas de sulcos, ravinas e de formação de voçorocas. O autor afirma que a textura arenosa dos solos encontrados na área não origina agregados e faz com que o vento se encarregue de acelerar a arenização pela própria mobilização eólica.

Quaresma (2008) investigou o surgimento de células de areais em áreas de solos arenosos, bem como suas possíveis transformações decorrentes da ação antrópica na Estação Ecológica de Jataí (EEJ), localizada no município de Luiz Antônio-SP. O autor faz um alerta e destaca que o desenvolvimento de manchas arenosas, no estado de São Paulo, não poderia ser classificado como processo de desertificação, em virtude do tipo de clima e da quantidade pluviométrica.

No município de Buritizeiro-MG, Trindade (2007) pesquisou a influência dos condicionantes litoestruturais e geoquímicos no desenvolvimento de leques arenosos e na origem de processos erosivos, denominados pelo autor de arenização. $\mathrm{O}$ autor afirma que a dinâmica hídrica é uma das condicionantes que influenciam e intensificam os processos de formação dos leques arenosos na área.

Para o sudoeste do estado do Piaú, Silva (2014) adotou o conceito de arenização para caracterizar a erosão do solo em Gilbués. Os processos erosivos atuantes naquela área são denominados oficialmente pela literatura científica (VASCONCELOS SOBRINHO, 1983; FERREIRA et al., 1994; BRASIL, 2004) como núcleo de desertificação. Entretanto, Silva (2014), ao aprofundar a discussão conceitual sobre desertificação e utilizar informações sobre o regime e ritmo pluviométrico, afirma que o processo não deve ser considerado como desertificação em decorrência de a região apresentar condições climáticas bem diferentes das áreas sujeitas à desertificação. Constatação similar, defendida por Sales (1998), que por meio da perspectiva climática (índice de aridez) aponta avaliações e críticas sobre o enquadramento da região como área suscetível a desertificação.

Em Mato Grosso, as discussões iniciais sobre o processo de arenização foram desenvolvidas por Costa (2015) e Nogueira (2017) na bacia do córrego Guanabara, munícipio de Reserva do Cabaçal. A pesquisa elaborada por Costa (2015) revelou que as causas dos problemas erosivos lineares se situam nos compartimentos com pequenas colinas e na Revista Cerrados, Montes Claros/MG, v. 18, n. 1, p. 331-351, jan./jun.-2020. 
SILVA, I. A. S.

Natureza em movimento: investigações desenvolvidas por Dirce Suertegaray para estudos sobre arenização

ocorrência do Neossolo Quartzarênico Órticos - tipo de solo desenvolvido sobre substrato rochoso formado por arenitos muito friáveis. Conforme Nogueira (2017, p. 80), “a suscetibilidade à erosão, com escoamento concentrado das águas de chuva, é maior na encosta do vale, pois, a energia de escoamento é maior e potencializa o desencadeamento e/ou aprofundando de ravinas".

Por meio desses estudos, nota-se que, além do Rio Grande do Sul, o conceito arenização vem sendo utilizado em outros estados brasileiros para caracterizar as feições arenosas (Figura 6) que morfogeneticamente estão associadas a características litológicas (rochas sedimentares) em regiões com condições climáticas específicas e disponibilidade hídrica.

Suertegaray (2020, p. 31), complementa que em Quaraí-RS, “os processos associados à gênese dos areais, considerando a dinâmica da natureza, estão vinculados a dinâmica hídrica superficial e de subsuperfície, além da ação do vento”. Conforme esta autora, "o processo de erosão, mais intenso em período de chuvas torrenciais, promove a erosão e o transporte de areias constituintes das formações superficiais, que sobrepõem o substrato arenítico" (SUERTEGARAY, 2020, p. 32).

Para a região de Gilbués, onde predomina superfícies erodidas, Silva (2020, p. 69) afirma que as "feições erosivas revelam a interação de processos, que se configuram essencialmente naturais e, em algumas áreas, são antropogênicos”. Como metáfora, este autor destaca que as feições erosivas são arquiteturas da natureza.

Em Mato Grosso, segundo Nogueira (2020, p. 128), as feições arenosas têm se destacado na paisagem do município de Reserva do Cabaçal, com manchas de areia de diversas amplitudes, bem como com desenvolvimento de processos erosivos. Nesta área, Ferreira; Silva (2020, p. 151) enfatizam que "fatores antropogênicos, como desmatamento e substituição da cobertura natural por pastagens, construção de estradas e pastoreio bovino, condicionam o surgimento de feições erosivas na paisagem". Entretanto, as características dos solos (arenosos) e a dinâmica climática também influenciam a origem e potencializam os processos de escoamento concentrado do fluxo d'água, dando condições à formação de feições arenosas na paisagem. 
SILVA, I. A. S.

Natureza em movimento: investigações desenvolvidas por Dirce Suertegaray para estudos sobre arenização

Figura 6: mosaico de fotografias indicando localidades com ocorrência de arenização.

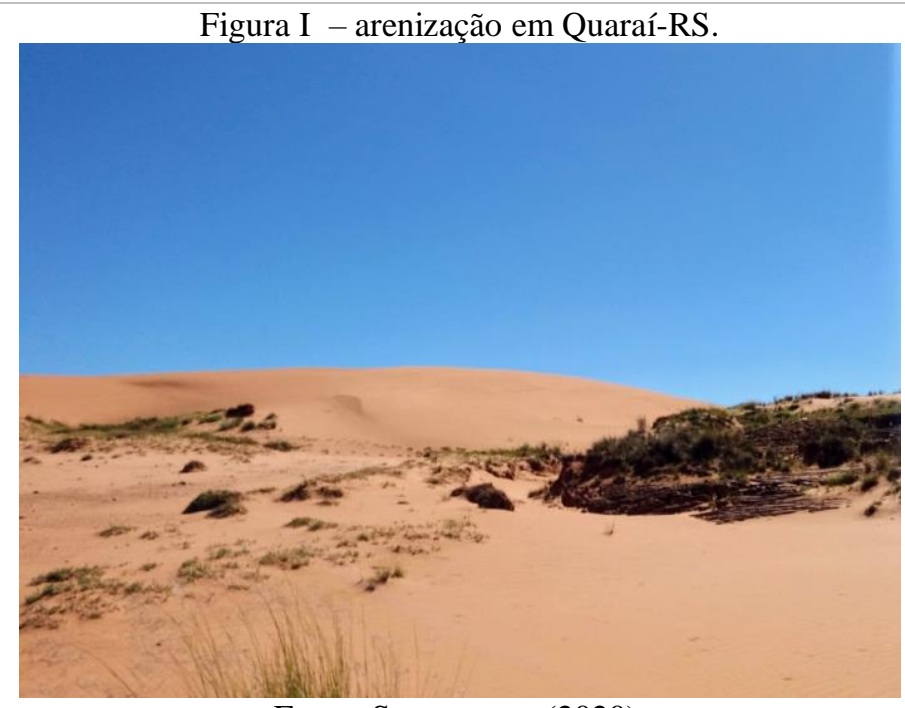

Fonte: Suertegaray (2020).

Figura III - arenização no Cerrado Paulista.

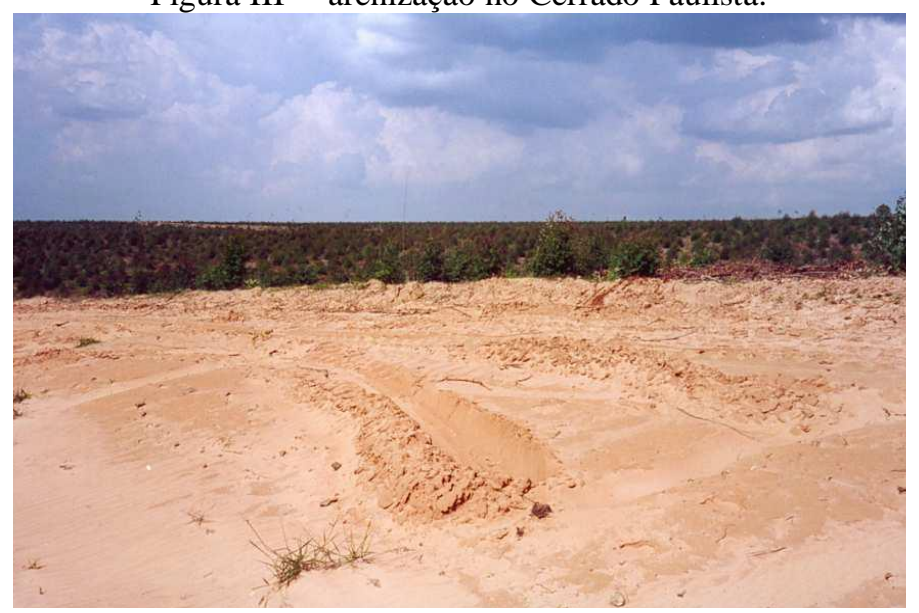

Fonte: Seabra (2006).

Figura V - Feições erosivas em Gilbués.

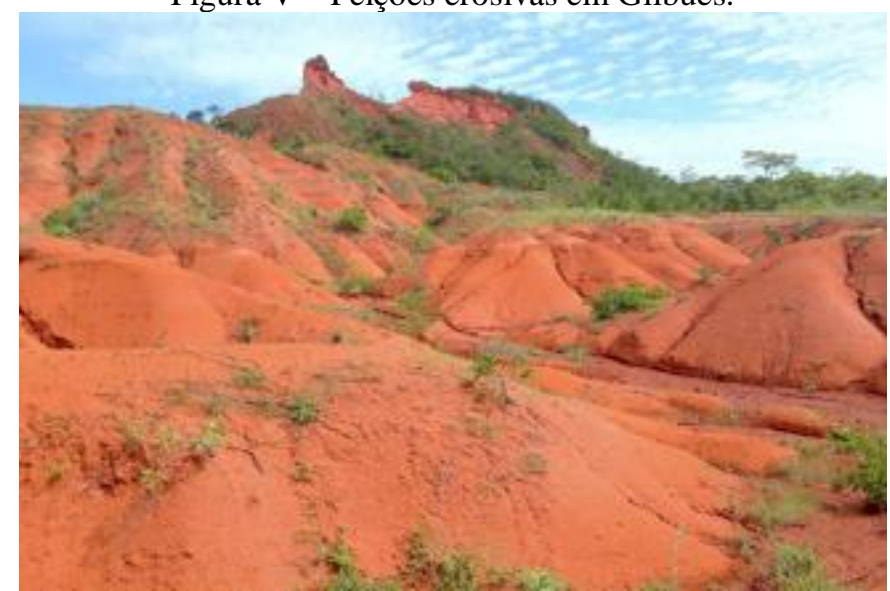

Fonte: Silva (2020).

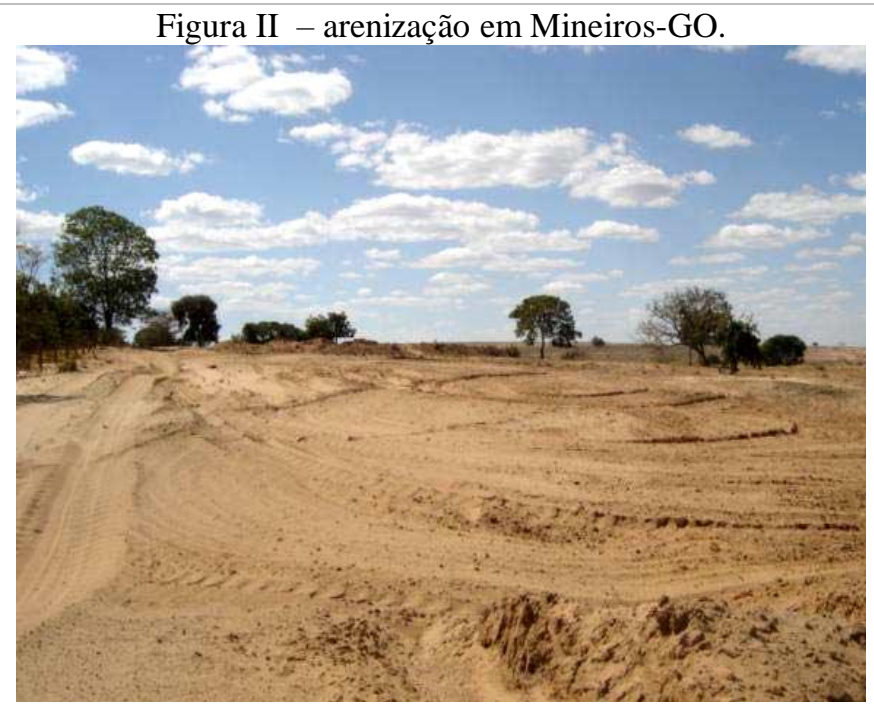

Fonte: Silva (2006)

Figura IV - arenização em Buritizeiro-MG.

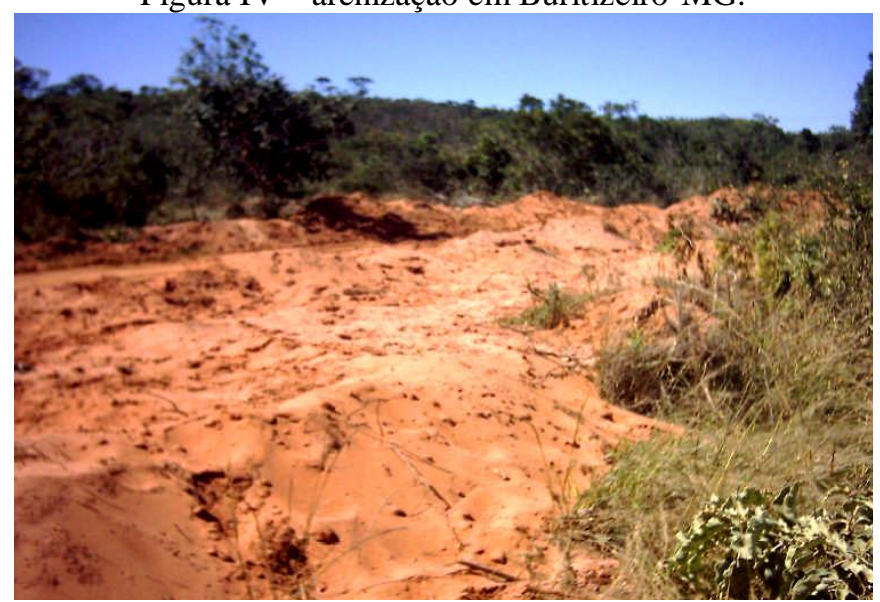

Fonte: Trindade (2007).

Figura VI - arenização em Reserva do Cabaçal-MT.

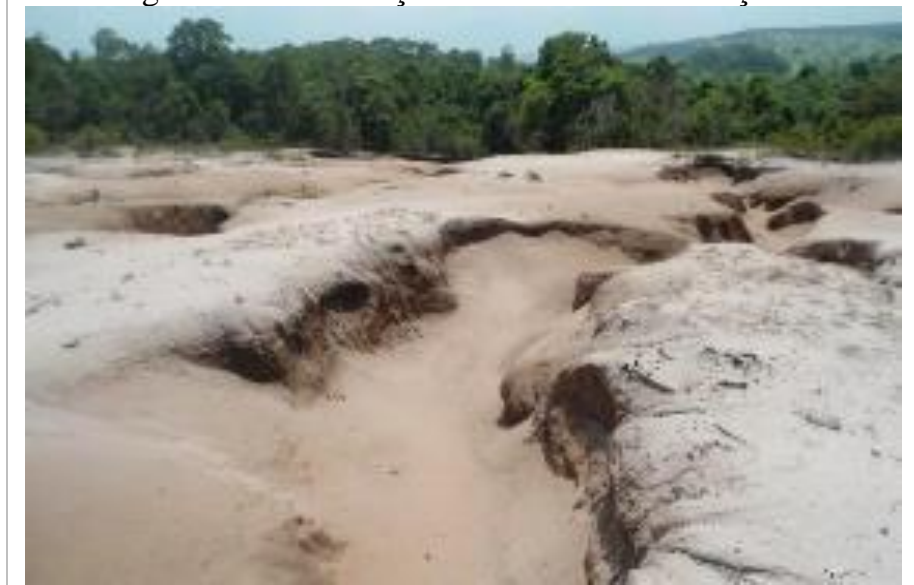

Fonte: Nogueira (2017).

Fonte: SUERTEGARAY, 2020; SILVA, 2006; SEABRA, 2006; SILVA, 2020; TRINDADE, 2007; NOGUEIRA; 2017. Organizado pelo autor. 
SILVA, I. A. S.

Natureza em movimento: investigações desenvolvidas por Dirce Suertegaray para estudos sobre arenização

Fundamentado nessas pesquisas, verifica-se que o processo de arenização no Brasil, desde que foi investigado inicialmente por Dirce Suertegaray até as pesquisas desenvolvidas recentemente, revelam processos naturais e antropogênicos, por vezes, semelhantes, observando, em diferentes paisagens naturais. As contribuições teóricas e a produção do conhecimento sobre arenização elaborado e difundido por Dirce Suertegaray teve um papel notável no avanço e enriquecimento teórico-metodológico para diversas pesquisas e em particular para estudos sobre a interpretação dos condicionantes e das dinâmicas que atuam na gênese e intensificação de areais em diferentes localidades do Brasil interiorizado.

\section{CONSIDERAÇÕES FINAIS}

A dimensão social e a busca pela conexão entre sociedade e natureza fazem parte da perspectiva defendida por Dirce Suertegaray e, inclusive, refletem-se em seus trabalhos até hoje, implicando, segundo ela, vivenciar a geografia de forma diferenciada. Essas análises são alternativas próprias e originais da ciência geográfica. Assim, especificamente a tese desenvolvida por Suertegaray (1987), no âmbito metodológico empregou abordagens envolvendo a interface natureza e sociedade para o estudo dos areais de Quaraí, feições arenosas que ocorrem no sudoeste do Rio Grande do Sul.

Devido ao impacto de suas pesquisas e textos, Dirce Suertegaray tornou-se referência na geografia brasileira no âmbito dos estudos sobre arenização e desertificação orientou importantes trabalhos (Iniciação científica, monografia, mestrado e doutorado) sobre esses temas que nortearam sua trajetória. Este brevíssimo texto está longe de mostrar toda a enorme dimensão das obras com grande repercussão, além de ser um balanço crítico sobre os estudos da desertificação e aspectos fundantes da arenização, apresentando um interessante cotejo entre natureza e sociedade.

Em geral, as investigações realizadas e aquelas que estão em andamento utilizam o conceito de arenização para caracterizar as manchas de areia e feições arenosas presentes na paisagem, em distintas localidades (RS, PR, MG, GO, MT, AM e PI). O artigo indicou que em algumas áreas, a natureza em movimento é responsável pela origem dos areais, mas as atividades sociais, realizadas de forma inadequada, promovem a intensificação do processo de arenização, em distintas paragens do território brasileiro. Com o aprofundamento teórico, verificou-se que o processo de arenização vem sendo reconhecido, espacialmente, no Brasil, 
SILVA, I. A. S.

Natureza em movimento: investigações desenvolvidas por Dirce Suertegaray para estudos sobre arenização

através dos estudos já elaborados, bem como a partir daqueles que derivam da continuidade das pesquisas (SILVA; SUERTEGARAY, 2018).

Que as "geografias" de Dirce Suertegaray sirvam de incentivo para estudantes, professores outros geógrafos e outras geógrafas. Este breve texto, elaborado às “pressas”, não poderia se encerrar sem uma breve incursão pela rica contribuição desta geógrafa, que navegou com maturidade pelas novas fronteiras do conhecimento, pelas novas fronteiras temáticas e epistemológicas da geografia desse vasto Brasil e mundo!

\section{AGRADECIMENTOS}

O autor agradece à Coordenação de Aperfeiçoamento de Pessoal de Nível Superior (CAPES) pela concessão de bolsa no curso de Doutorado em Geografia na Universidade Federal do Rio Grande do Sul.

\section{REFERÊNCIAS}

AB'SÁBER, A. N. A revanche dos ventos: derruição de solos areníticos e formação de areais na Campanha Gaúcha. Ciência e Ambiente - Universidade Federal de Santa Maria: Editora da UFSM. Vol. 1, n. 1, p. 7-31, 1995.

ALBUQUERQUE, A. R. C. Impactos Ambientais na Bacia do Igarapé do Leão: tendências à arenização. 1999. 120 f. Dissertação (Mestrado em Geografia), Programa de Pós-Graduação em Geografia, Universidade Federal do Rio de Janeiro. Rio de Janeiro, 1999.

ANTUNES, E. C. Recuperação de áreas degradadas por meio de recomposição vegetal em solos arenosos no sudoeste goiano. 2006. $171 \mathrm{f}$. Tese (Doutorado em Ciências Ambientais), Universidade Federal de Goiás, Goiânia, 2006.

BELLANCA, E. Uma contribuição à explicação da Gênese dos Areais do Sudoeste do Rio Grande do Sul. 2002. 85 f. Dissertação (Mestrado em Geografia), Universidade Federal do Rio Grande do Sul - UFRGS, Porto Alegre, 2002.

BRASIL, GOVERNO DO. Programa de ação nacional de combate à desertificação e mitigação dos efeitos da seca - PAN-Brasil. Brasília, DF: Ministério do Meio Ambiente. Secretaria de Recursos Hídricos. 2004.

COSTA, J. R. Diagnóstico, prognóstico e controle dos processos erosivos na bacia do córrego Guanabara, afluente do rio Cabaçal. 2015. 86 f. Dissertação (Mestrado em Recursos Hídricos). Universidade Federal de Mato Grosso. Cuiabá, 2015. 
SILVA, I. A. S.

Natureza em movimento: investigações desenvolvidas por Dirce Suertegaray para estudos sobre arenização

CORDEIRO, C, A.; SOARES, L. C. A. Erosão nos solos arenosos da região sudoeste do Rio Grande do Sul. Revista Brasileira de Geografia (IBGE), Rio de Janeiro, n. 39, p. 82-96, 1977.

FERREIRA, D. G.; MELO, H. P.; RODRIGUES NETO, F. R.; NASCIMENTO, P. J. S.; RODRIGUES, V. Avaliação do Quadro da Desertificação no Nordeste do Brasil:

Diagnósticos e Perspectivas. Anais da Conferência Nacional da Desertificação, Fortaleza. Brasília, Fundação Grupo Esquel Brasil. p. 7-55, 1994.

JORNAL BRASIL. LINS, L; DALTO, R. Ecologia: desertos. Rio de Janeiro, 27 de janeiro de 1992. p. 1. Disponível em:〈http://memoria.bn.br/pdf/030015/per030015_1992_00292.pdf> Acesso em 16 de agosto de 2019.

NOGUEIRA, A. M. Caracterização do processo de arenização na bacia hidrográfica do córrego Guanabara, Reserva do Cabaçal-MT. 2017. 104 f. Dissertação (Mestrado em Geografia), Universidade Federal de Mato Grosso. Cuiabá, 2017.

NOGUEIRA, A. M. Feições arenosas de Mato Grosso - As praias do Sertão: feições arenosas de Reserva do Cabaçal. In: SUERTEGARAY, D. M. A.; SILVA, I. A. S. (Org.). Brasil: feições arenosas. Porto Alegre: Compasso Lugar-Cultura, 2020. p. 127-138.

QUARESMA, C. C. Organizações espaciais físico/naturais e fragilidades de terras sob cerrado: abordagem sistêmica aplicada à escala local. 2008. 152 f. - Dissertação (Mestrado em Geografia) Universidade Estadual de Campinas - Unicamp, Campinas, 2008.

ROSSATO, D. M. S. Atividade humana como processo geomorfológico: o exemplo na bacia do rio Toropi-RS. 1981. Dissertação (Mestrado em Geografia), Universidade de São Paulo, São Paulo, 1981.

SALES, M. C. L. Estudo da degradação ambiental em Gilbués-PI: Reavaliando o "núcleo de desertificação". 1998. 181 f. Dissertação de Mestrado em Geografia - Faculdade de Filosofia, Letras e Ciências Humanas, Universidade de São Paulo (USP), São Paulo, 1998.

SEABRA, F. B. Análise Geossistêmica Aplicada ao Estudo da Fragilidade das Terras em Áreas do Cerrado Paulista. 2014. 119 f. - Dissertação (Programa de Pós-Graduação em Geografia - Instituto de Geociências), Universidade Estadual de Campinas - Unicamp, Campinas, 2014.

SILVA, R. A. A. Arenização/desertificação no setor sul da Alta Bacia do Rio Araguaia (GO-MT): distribuição e fatores condicionantes de formação de areais. 2006. $140 \mathrm{f}$. Dissertação (Mestrado em Geografia), Universidade Federal de Goiás - UFG, Goiânia, 2006.

SILVA, L. A. P. Narrativas das percepções e conectividades de caminhantes nas paisagens dos areais pampeanos: perspectivas ambientais para geração de ambiências. 2008. 155 f. Dissertação (Mestrado em Geografia) - Universidade Federal do Rio Grande do Sul, Porto Alegre, 2008. 
SILVA, I. A. S.

Natureza em movimento: investigações desenvolvidas por Dirce Suertegaray para estudos sobre arenização

SILVA, I. A. S. Clima e arenização em Gilbués-Piauí: dinâmica das precipitações e a vulnerabilidade da paisagem aos eventos pluviais intensos. 2014. $184 \mathrm{f}$. Dissertação de mestrado em Geografia (IESA) - Universidade Federal de Goiás - Goiânia, 2014. Disponível em: 〈http:// http://repositorio.bc.ufg.br/tede/handle/tde/3036>. Acesso em: 26 de fevereiro de 2020 .

SILVA, I. A. S. Feições arenosas do Piauí - Malhadas e grotas: feições abstratas. In: SUERTEGARAY, D. M. A.; SILVA, I. A. S. (Org.). Brasil: feições arenosas. Porto Alegre: Compasso Lugar-Cultura, 2020. p. 53-71.

SILVA, I. A. S.; SUERTEGARAY, D. M. A. Arenização no Brasil: um comparativo com as variações climáticas regionais. Revista de Geografia - PPGEO - UFJF, Juiz de Fora/MG, v.8, n.2, (XIII SBCG 2018), p.01-11, 2018.

SOUTO, J. J. P. Deserto, uma ameaça? Estudos dos núcleos de desertificação na fronteira sudoeste do Rio Grande do Sul. Porto Alegre: Secretaria de Agricultura/DRNR, 1985.

SUERTEGARAY, D. M. A. A Trajetória da Natureza: um estudo geomorfológico sobre os areais de Quaraí-RS. 1987. 243 f. Tese (Doutorado em Geografia) - Faculdade de Filosofia, Letras e Ciências Humanas, Universidade de São Paulo (USP), São Paulo, 1987.

Deserto Grande do Sul: controvérsias. 2. ed. Porto Alegre: Editora da Universidade, UFRGS, 1998.

. O Rio Grande descobre os seus "desertos". Ciência e Ambiente -

Universidade Federal de Santa Maria: Editora da UFSM, v. 11, n. 1, p. 33-52, (jul. 1995).

Desertificação: recuperação e desenvolvimento sustentável. In: GUERRA, A. J. T.; CUNHA, S. B (Orgs). Geomorfologia e Meio Ambiente. 6. ed. Rio de Janeiro: Bertrand Brasil, 2006.

SUERTEGARAY, D. M. A.; GUASSELLI, L. A.; VERDUM, R. Atlas da Arenização Sudoeste do Rio Grande do Sul. Porto Alegre: Secretaria da Coordenação e Planejamento do Estado do Rio Grande do Sul e Secretaria da Ciência e Tecnologia Governo do Estado do RS, 2001.p. 84.

SUERTEGARAY, D. M. A. Arenização: análise morfogenética. In: SUERTEGARAY, D. M. A.; GUASSELLI, L. A.; PIRES DA SILVA, L. E. (org.) Arenização: natureza socializada. Porto Alegre: Compasso Lugar Cultura e Imprensa Livre, 2012, 600 p.

. Feições Arenosas do Rio Grande do Sul - Os areais de Quaraí. In:

SUERTEGARAY, D. M. A.; SILVA, I. A. S. (Org.). Brasil: feições arenosas. Porto Alegre: Compasso Lugar-Cultura, 2020. p. 29-38.

STIPP, M. E. F. A ocupação do solo e a problemática da arenização em Paranavaí-PR. 2006. 178 f. Tese (Doutorado em Geografia), Universidade de São Paulo, São Paulo, 2006. 
SILVA, I. A. S.

Natureza em movimento: investigações desenvolvidas por Dirce Suertegaray para estudos sobre arenização

TRINDADE, W. M. Condicionantes litoestruturais da origem e desenvolvimento de processos erosivos e arenização na Bacia do Rio do Formoso - Buritizeiro-MG. 2007. 97 f. Monografia (Graduação em Geografia), Departamento de Geociências, Universidade Estadual de Montes Claros. Pirapora, 2007.

VASCONCELOS SOBRINHO, J. Processos de desertificação ocorrentes no nordeste do Brasil: sua gênese e sua contenção. Recife: SUDENE, 1983. 101p.

VERDUM, R. Approche géographique des deserts dans lês communes de São Francisco de Assis et Manuel Viana - Etat do Rio Grande do Sul - Brésil. 1997. 211f. Tese (Doutorado), Université de Toulouse II (Le Mirai), U.T.H, França. 1997.

VERDUM, R; BINDA, A. L.; VIEIRA, C. L.; SANCHES, F. O.; CANEPPELE, J. C. G; GASS, S. L. B. Feições arenosas do Rio Grande do Sul - Os mitos e as realidades dos areais do Pampa Gaúcho. In: SUERTEGARAY, D. M. A.; SILVA, I. A. S. (Org.). Brasil: feições arenosas. Porto Alegre: Compasso Lugar-Cultura, 2020. p. 13-27.

\section{Autor}

Ivamauro Ailton de Sousa Silva - Possui Graduação e Mestrado em Geografia pela Universidade Federal de Goiás (UFG). Atualmente é Doutorando pelo Programa de PósGraduação em Geografia pela Universidade Federal do Rio Grande do Sul (UFRGS).

Artigo recebido em: 23 de maio de 2020.

Artigo aceito em: 26 de junho de 2020.

Artigo publicado em: 30 de junho de 2020. 